\title{
1. The makings of an authority in science
}

It is safe to say that evaluations are ubiquitous in science. They come in many forms and shapes. On the individual level, researchers evaluate and are evaluated nearly every day. Colleagues openly scrutinize and criticize one another in scholarly seminars, hopefully seeking to push ideas and texts forward (e.g. Bennett 1998; Zuckerman and Merton 1971). In closed and quasi-secretive settings, peers assess manuscripts for articles and books, as well as applications for positions and research resources. The outcomes of these assessments typically become the main basis for decisions that concern who to publish, who to hire, and who to fund (e.g. Lamont 2009; Langfeldt and Kyvik 2011; Musselin 2013; Zuckerman and Merton 1971).

Similarly, on the organizational level, research organizations evaluate and are evaluated as well. Universities themselves regularly launch sweeping internal reviews, allegedly attempting to identify strengths and weaknesses within and between their different sub-units. The results of such reviews are commonly linked to non-trivial resource schemes, which usually reward groups, centres, institutes and departments that come out well (e.g. Bomark 2016; Gläser et al. 2004; Wedlin and Pallas 2017). With regular intervals, governments evaluate publicly financed universities, often employing bibliometric data that supposedly maps and reflects the impact of published research. Evaluations like these are most often also linked to resource allocations that reward research organizations which display strong performances (e.g. Blockmans et al. 2014; Engwall and Nybom 2007; Gläser and Laudel 2007; Weingart 2005). And large media conglomerates continuously rank universities, scrutinizing their aggregated academic outputs through prespecified metrics with the intention of comparing entire organizations. Such rankings can have considerable implications for universities. Rankings contribute to processes that form identities, shape hierarchies and determine which activities are seen as worthy of pursuing among research organizations 
(e.g. Elsbach and Kramer 1996; Espeland and Sauder 2007; Sauder and Espeland 2009; Pallas and Wedlin 2014; Wedlin 2006, 2007, 2011).

I have outlined only a few examples here, but they probably suffice to highlight the wide extent and broad variety of evaluations in science. As Robert K. Merton (1973: 276) fittingly argued, researchers and research organizations are 'subject to rigorous policing, to a degree perhaps unparalleled in any other field of activity'. Evaluations clearly hold a central position in science. There appears to be an almost innate and unsatisfiable demand for them.

In the midst of this wide extent and broad variety of evaluations, however, some seem to command a greater dose of authority than others. In Europe, as of late, cursory observations tell us that one particular set of evaluations has stood out from the rest. A few times per year, the European Research Council (ERC) announces the results of its calls for funding applications. Now, if the ERC was like most other funders in Europe, its announcements would presumably wax and wane, quickly surfacing and dissipating with equal rapidity among loads of other information competing for the limited attention of the surrounding research community. But the ERC seems to be more than just another funder. The results of its calls spread widely, garnering much interest as they are released for the European research community to see. The public release of these results tends to create a flurry of semi-anxious activities, most prominently noted in how scientists, department heads, institute directors, faculty deans, university vice chancellors, national research council officials, and politicians on the national and continental level all invest great effort into analysing and discussing who was funded by the ERC, where these recipients will be based, and what their successful applications might have contained.

Part of this interest is presumably related to the generous resources at play in every ERC call. The great bulk of scientists in universities must regularly seek and access funding from external parties so as to enable any significant research time (e.g. Braun 1998; Fochler et al. 2016; Heinze 2008; Laudel 2006a, 2006b; Roumbanis 2019a; Sigl 2016). Depending on where applicants are situated in their careers, ERC grants range between $€ 1.5$ million and $€ 2.5$ million for five years of research. Such monetary amounts and duration periods usually characterize funding schemes that feature several co-applicants and provide support for entire research programmes. ERC grants, however, are almost exclusively targeted at single applicants. The individual basis of these grants makes them considerably larger than most - if not all - other comparable 
funding schemes in Europe. We should, in light of this, perhaps not be so surprised to learn that ERC grants attract much interest.

But could there possibly be something more than generous resources at play here? Reading newsletters, editorials and essays in various science media outlets during the past 15 years or so, it appears as if scientists, universities and even entire countries are increasingly wont to measure their performance in science on the basis of ERC evaluation results. For instance, shortly after the ERC's inaugural round of funding allocations, ScienceBusiness wrote emphatically about 'exam results' that 'give new boasting rights to the winners - and prove embarrassing to others' (Hudson 2008). Senior professors, long-time administrators and veteran journalists have often been heard speaking about the emergence of an outright 'Champions League' (e.g. Amos 2012; Enserink 2007; Maasen 2009; THE 2016) in European science. And, today, it is becoming increasingly apparent that many individuals and organizations in the research community approach the results of ERC evaluations as a benchmark of scientific quality whose reach extends over large swathes of Europe (e.g. Cieciura 2017; CNRS 2017; Deane 2017; Morgan 2018; Opsvik 2019; Oxford 2017; Stockero 2017).

The development of this ERC-based benchmark is remarkable not only for its wide geographic reach, but also because it is based on evaluation procedures that are more than three centuries old. Like most other research funders, the ERC uses peer review as means for evaluating the quality of applications that scientists submit to one of its three broad disciplinary classifications, which are Life Sciences (LS), Physical Sciences and Engineering (PE) and Social Sciences and Humanities (SSH). The ERC's procedures for evaluating quality should, as such, be nothing new to science. The spread of an ERC-based benchmark of scientific quality is even more striking if we consider two additional aspects that relate to the ERC's peer review procedures. To begin with, on a general level, notions of quality in science display considerable variation across disciplines (e.g. Davis 1971; Hargens and Hagstrom 1967; Hermanowicz 2013; Lamont 2009; Whitley 1984). There is, at best, vague and tacit consensus among researchers when it comes to what scientific quality is. Moving on, in more particular terms, the ERC also employs one of the most ambiguous forms of peer review (e.g. Langfeldt and Kyvik 2011; Roumbanis 2019b). It is inherently challenging to evaluate quality on the forward-looking basis of applications for funding toward research that has not been conducted yet. Taking these additional aspects into account, one very conspicuous development is that the ERC's evaluations have 
seemingly been transformed into an agreed-upon, almost unambivalent benchmark of present-day scientific quality, understood and accepted as a common yardstick with which performance in research can be satisfactorily gauged across disciplinary domains. Notably, while considerable criticism has been directed at the age-old practice of peer review (e.g. Horrobin 1996; Roumbanis 2019b; Roy 1985; Wennerås and Wold 1997), as well as at the growing use of peer review-based bibliometrics (e.g. Blockmans et al. 2014; Burrows 2012; Weingart 2005; Werner 2015), the research community in Europe appears to have quickly rallied around the results of ERC peer review evaluations, without much overt debate and discussion. These results are nowadays compared with, and placed alongside or above, many of the more established markers of quality in science, such as the reception of certain intra-professional prizes and publication in select scholarly journals.

Considering how this new research funder was founded by the European Commission (EC) in 2007, the ERC's ongoing saga will soon reach its 15 -year anniversary. In spite of its relatively short life, the ERC has seemingly risen to and assumed an authoritative position. I am particularly interested in how this funder, through its evaluations of applications, has developed into what we at this stage of the present book can understand as an arbiter of scientific quality. What happened here? How did the ERC's evaluation results become a benchmark of quality in European science? And what does the emergence of a quality arbiter imply for science in Europe?

\section{BLOCKS, PROJECTS AND CHANGES IN THE FUNDING OF RESEARCH}

The questions I raise about the ERC appear timely when put against a backdrop of broader changes relating to the growing salience of research funding for the academic activities of scientists, departments, faculties and universities. While full engagement with these research funding changes lies beyond the scope of this book, I suggest that they can supply the initial fodder on our path toward understanding the ERC's development into an arbiter of scientific quality in Europe.

Funding for research in universities can be classified according to whether it is based on internal or external resources. Traditionally, in European universities, the great majority of resources were provided directly by governments. For long periods of time, only minor resources came indirectly through intermediaries, such as publicly 
controlled research councils or privately held foundations (e.g. Benner and Sandström 2000; Braun 1998; Hicks 2012; Lepori et al. 2007; Musselin 2013). In line with Auranen and Nieminen's (2010) classification, I approach direct resources from governments as internal funding, because universities have most often been afforded relatively large degrees of autonomy to decide on the subsequent distribution of this funding among faculties and departments. That said, I regard indirect resources from research councils and foundations as external funding, as universities have usually not been able to control how this funding is distributed internally.

Generally, up until the early 1980s, European governments and their respective universities remained in close connection to one another (e.g. Geuna 2001; Lepori 2006). Most research, as I hinted at above, was funded directly by governmental resources. But, in the years that followed, several governments adopted and embarked upon a string of market-flavoured reforms. These reforms were primarily fuelled by a wave of political support for neoliberal ideas, starting in the United Kingdom (UK) and subsequently spreading to large parts of Western Europe. The main ingredients of these ideas, as they applied to public sectors, were seemingly innocuous notions of efficiency and competition for scarce resources (e.g. Hood 1991, 1995; Pollitt et al. 2001; Verhoest et al. 2004). Such notions, however, would have considerable and enduring consequences for the relations between internal and external research funding in universities. These consequences were perhaps more apparent throughout the welfare states of Scandinavia than anywhere else in Europe.

I suggest that Sweden constitutes a context within which internal and external funding proportions clearly and rapidly shifted as a consequence of sweeping reforms to its structures for research financing. To begin, in Swedish universities, the large majority of research resources typically came from centralized and periodic governmental grants. Vice chancellors and chair professors subsequently distributed these grants internally to long-term research programmes in faculties and departments (Edlund and Wedlin 2017). Additional resources were available through a patchwork of small public research councils and private foundations. While foundations were more or less free to target any disciplines they wished, research councils were often bound by statutes and mandates that limited their funding to specific disciplinary domains. Despite these differences, both public research councils and private foundations distributed resources directly to individual scientists at the helm of research 
groups conducting short-term projects in universities. Research council and foundation resources were, as such, largely beyond the control of departments and faculties. That said, this external funding constituted only minor parts of universities' total research resources and were merely meant to provide small supplements on top of large governmental block grants (Engwall and Nybom 2007). Internal funding undoubtedly remained dominant.

In similarity with other public sectors across Scandinavia, the entry of neoliberal ideas and market-flavoured reforms into the Swedish public sector during the late 1980s and early 1990s brought about important implications for the funding of university research. While vice chancellors and chair professors still distributed governmental block grants once these arrived at universities, these distributive matters were decided in closed-door meetings with politicians (Edlund and Wedlin 2017). There was presumably little - if any - room left for open competition over the final allocation of block grants. Now, however, the new message from politicians was that Sweden's research funding landscape needed to be clarified and consolidated. To this end, many small public research councils were discontinued, while several others were merged with one another. The remaining councils would increase the efficiency with which research resources were employed by allocating their funding through merit-based competition. Funding should, as politicians stressed at the time, be distributed directly to those capable of making the most productive use of it. By extension, it was believed that these new allocation mechanisms could improve the research performance of the entire Swedish university system (e.g. Benner and Sörlin 2007; Engwall and Nybom 2007; Hallonsten and Hugander 2014; Hallonsten and Silander 2012).

I argue that this emphasis on competition and efficiency could be seen clearly in the increasing importance that external funding was assuming. The centralized and periodic features of block grants clashed almost head-on with new ideas about flexible, responsive and demand-driven research resources. These ideas typically favoured short-term projects led by individual scientists over long-term research programmes adjudicated to departments and faculties (Engwall and Nybom 2007). Resources from public councils and private foundations quickly transitioned from being considered mere complements to becoming integral parts of how research was funded in Swedish universities. By the late 2000s, the proportions of internal and external funding were almost equal (Hallonsten and Silander 2012). And, a few years into the 2010 s, the proportion of external funding 
surpassed that of internal funding (e.g. Öquist and Benner 2012; Frølich et al. 2018). These changes marked a structural turning point for research funding in Sweden.

Although they may have been particularly noticeable in Scandinavia and Sweden, similar changes can also be observed across Europe (e.g. Bégin-Caouette et al. 2017; Hicks 2012; Lepori et al. 2007). One of the most central implications deriving from these changes is that scientists, in order to conduct research, must spend increasing amounts of time applying for external funding. The growing prevalence of individually led short-term projects in Europe has placed many researchers under more or less continuous pressure to submit applications for funding (e.g. Fochler et al. 2016; Heinze 2008; Roumbanis 2019a). As the importance of external research funding in universities has increased, I propose that the role played by evaluations of applications has also been transformed. Evaluators at most research councils and foundations presumably read and review large numbers of applications, but are often only able to endow low double-digit percentages of applicants with some of the external funding that is at stake. The emphasis on subjecting scarce public resources to competitive evaluations evidently bars a great majority of scientists from being funded. Evaluations of applications, against this backdrop, can be approached as central and recurring selection mechanisms in European science. By defining 'losers and winners' (Langfeldt 2006: 32), these evaluations separate and elevate researchers who are deemed as worthy of funding from others who are not seen in the same light. The notion of funding only a minor number of scientists after they have competed against large groups of applicants subsequently sends clear signals that evaluators found these few researchers particularly meritorious and promising. Scientists who access external funding under these demanding conditions are prone to be approached as exceptionally talented. In sum, with the growing significance of individually and competitively allocated funding, evaluation results have been injected with an inherent potential to become impactful markers of scientific quality.

\section{STATUS PERSPECTIVES ON RESEARCH FUNDING}

By now, I have made the broad case for approaching evaluations of external funding applications as instances that may render quality markers in science. However, we still want to understand how the ERC's particular evaluations have developed and become more authoritative than most others in Europe. 
There is, to be sure, scholarly work done on the ERC. While valuable, much of this work starts off from an established and accepted ERC, before analysing the consequences of its research funding allocations. On the individual level, Nedeva et al. (2012) examined the implications of ERC resources among early-career scientists in seven European countries. The findings of this study showed that receiving funding from the ERC was regarded as a 'life-changing event' (Nedeva et al. 2012: 73), which translated into enhanced confidence, increased international visibility and improved chances at accessing resources in the future. Moreover, on the organizational level, Edler et al. (2014) explored the relations between ERC financing and governance changes in a group of universities from eight countries. Edler and colleagues demonstrated that 'in-between' universities (that is, those with shifting levels of research funding access) were the most likely to alter strategies and human resource policies in attempts at associating with resources from the ERC. These universities regularly reformed and revamped their career structures and bonus systems, all in the name of fostering, retaining and/or recruiting recipients of ERC funding. Also on the organizational level, Cruz-Castro et al. (2016) analysed the responses of Spanish universities after researchers in certain departments and faculties received ERC financing. Their work showed how certain universities in Spain, despite being centrally controlled by the state, were able to make local exceptions and devise prizes, promotions and reduced teaching loads for ERC funding recipients. From previous literature, we thus know that the ERC's financing has brought about a range of consequences, spanning many analytical levels of science in Europe.

In this book, I am also interested in the implications of ERC funding for individuals and universities. I corroborate some previous findings, but also highlight some new consequences that can be related to the ERC's financing of research. That said, my take differs from past literature. I suggest that the consequences of ERC funding can only be understood satisfactorily by paying close attention to their antecedents as well. When focus is put on the implications of this financing, we sidestep how the ERC's funding has been able to achieve these consequences. I thus argue that we need to take a step back, expand our gaze, and direct additional efforts toward understanding how the preceding ERC evaluations successively reached their authoritative position in the very first place. In doing so, I believe we will be able to build a more complete picture of the ERC's development than that which is offered by extant literature. Although scant, work on building this picture is certainly under way. 
König (2017), for instance, gave us a detailed account of how the ERC first came about. His focus was primarily placed on the political processes behind the ERC's creation, but König also outlined some considerations that played into the ways in which ERC evaluations were initially organized. And, more specifically, Luukkonen (2012) highlighted how the ERC's evaluators understand the notion of excellence in applications for funding. Although they provide us with extensive empirical insights, both of these contributions remain descriptive. As such, given that König and Luukkonen do not engage with and connect to any larger bodies of theory, it seems as if the potential residing in their insights is not fully exploited.

To begin, I suggest that our knowledge of the ERC can be further advanced by approaching the apparent authority of its peer review evaluations with theoretical fodder from the sociology of science. As indicated by Zuckerman and Merton (1971), for more than 300 years peer review has been the primary procedure for evaluating quality in science. With the formation of learned societies in the $1600 \mathrm{~s}$, and the concomitant launch of journals with which to adjudicate and disseminate scientific discoveries, researchers sought informed reviews of their work by experienced peers before any claims were accepted and authenticated as valid entries into a growing body of science-based knowledge. Up until today, peer review remains dominant as the central means for evaluating scientific quality. As Lamont (2009) proposed, one of the main elements behind this long-standing dominance may be the - implicit or explicit - notion that peers can disregard their own tastes, opinions and preferences in order to collectively and collegially arrive at impartial reviews concerning quality. For instance, throughout his famous 'ethos of science', Merton (1973) highlighted how evaluations of knowledge claims should be entirely grounded in merit-based criteria, without any personal interests interfering. Peer review, in this perspective, is a meritocratic procedure that relies on competent readers and discussants to identify scientific quality throughout ideas and texts. Indeed, peer review is often approached as a means to reduce biases, including tastes, opinions and preferences, which may otherwise compromise the impartiality of evaluations in science (e.g. Chubin and Hackett 1990; Merton 1973; Zuckerman and Merton 1971).

While there is little question about its centrality, peer review has also been the target of criticism directed at its reliability and validity as a procedure with which to accurately approximate notions of quality (e.g. Horrobin 1996; Roumbanis 2019b; Roy 1985; Wennerås and Wold 
1997). Previous literature tells us that several social considerations regularly - and perhaps inevitably - enter into any evaluations of scientific quality. For example, in their seminal study, Cole et al. (1981: 885) argued that the 'luck of the reviewer draw' plays an important role in peer review procedures, suggesting these may be characterized as resting on mixes of merits and random elements. Other studies have shown that cronyism (Travis and Collins 1991), favouritism (Porter and Rossini 1985) and opportunism (McCutcheon 1997) are common elements when peers conduct reviews of research work. Altogether, this literature provides ample support for the notion of moving away from an 'absolute definition' to a 'social definition' (Cole and Cole 1973: 23-4) of quality in science. Such a move means that peer review evaluations are not disembedded procedures in which impartial criteria come into play with consistency. Instead, these evaluations can be understood as procedures where various views about quality in science are discussed and debated, often leading to different assessments of the ideas and texts that are up for scrutiny. Although it can be seen in peer review within disciplines (e.g. Davis 1971; Roumbanis 2019b), this variety of views is most particularly noticeable across disciplinary domains (e.g. Hargens and Hagstrom 1967; Lamont 2009; Whitley 1984).

Because the notion of quality has traditionally been approached in different ways across disciplines, we would not expect single evaluation results to become accepted as broad-spanning markers of scientific quality. Some evaluations of external funding applications, such as those conducted by the ERC, nonetheless appear to transcend the notion of disciplines, unexpectedly spreading as quality markers over large swathes of European science. When evaluations spread this way, however, they open up for issues that extend beyond assessments of quality and allocations of funding (cf. Allen and Parsons 2006; Cattani et al. 2014).

The status literature can help us shed light on many issues that relate to the spread of certain evaluations. More specifically, when some applicants are separated and elevated as particularly merited and promising in evaluations whose results subsequently spread across disciplines, we can assume that not all who are reached by these results will be able to assess their accuracy. It should, for instance, be challenging for sociologists to interpret the accuracy of selective funding allocations in any given call for applications from physicists. And physicists would probably face similar challenges if attempting to assess evaluation results among sociology applications. The status literature, in this regard, shows how actors who find themselves in situations and contexts that they possess 
relatively little previous knowledge of are prone to adopt a social orientation when estimating the worth of others. More specifically, when faced with such situations and contexts, actors tend to use a variety of cues that serve as more or less satisfactory replacements for quality (e.g. Beckert and Musselin 2013; Granovetter 1973, 1974; Uzzi 1996, 1997). One of the most potent replacements is status, because it is widely regarded as an accurate reflection of underlying quality (e.g. Henrich and Gil-White 2001; Magee and Galinsky 2008; Podolny 1994, 2005). When it comes to science, degrees from certain universities (Hargens and Hagstrom 1967), memberships in specific academies (Merton 1968) and endorsements by particular researchers (Zuckerman 1967) play an important role as replacements for scientific quality, especially when researchers attempt to assess the worth of others whose work they are not familiar with. Tellingly, along the lines of these arguments, status has traditionally replaced quality as the primary feature of the social order in science (e.g. Ben-David and Sullivan 1975; Cole and Cole 1973; Merton 1957, 1968; Zuckerman 1977, 1992).

As Thorstein Veblen (1953 [1899]) so emphatically emphasized more than 120 years ago, contexts where quality is unclear and challenging to assess may also become fertile grounds for status creation. Veblen's ideas about the creation of status have subsequently branched out into three important approaches. One of them is closely connected to Max Weber's (1968 [1922]) classical essay on the role of social closures. Here, status comes about when actors that display worthy attributes and/ or behaviours seclude themselves in exclusive groups. Actors in such groups tend to gather around common projects of distinction and collective beliefs of superiority. In order to sustain their exclusivity, these groups deliberately restrict access by way of scarce positions and elusive membership conditions (e.g. Bourdieu 1984, 1986; Elias and Scotson 1994 [1965]; Ridgeway 2014).

Another salient approach to status creation revolves around a string of studies conducted by Joel Podolny and colleagues (e.g. Benjamin and Podolny 1999; Podolny 1994, 2005; Podolny and Phillips 1996) that deal with the role of affiliations. Their approach draws heavy inspiration from social network research, where previous interactions are regarded as central sources and conduits of information for actors that are about to transact with unknown others (e.g. Granovetter 1973, 1974). Building on this research, Podolny and colleagues suggest that status comes into existence when actors of different social standing are publicly affiliated with one another. More specifically, lower-standing actors gain status 
in situations and contexts where they are openly connected to actors of higher standing (e.g. Podolny 1994, 2005; cf. Gould 2002). The status-creating role of affiliations, in this sense, bears close parallels to the age-old adage that 'you are who you hang out with'.

While social closures and affiliations have been extensively examined through previous literature, an additional approach has emerged as of late and developed into an impressive body of knowledge. A third approach thus refers to the work of Wendy Espeland and Michael Sauder (e.g. Espeland and Sauder 2007, 2016; Sauder 2005, 2006; Sauder and Espeland 2006, 2009; see also Sauder and Fine 2008), which focuses on the involvement of intermediaries in status creation. Their work extends past the assumption of dyadic interactions between actors that attempt either to enhance their own status or to endow others with status. Espeland and Sauder revisit the slightly bypassed notion that status-creating processes often involve actors from three analytically distinct groups. For example, Hans Speier (1935) emphasized that status creation can be regularly regarded as the outcomes of interactions between 'bearers', 'bestowers' and 'observers'. Charles Wright Mills (1963) pointed to the importance of considering 'claimants' and 'conferrers', as well as the situations and contexts within which status-creating processes unfold. And William Goode (1978: 13) stressed that status creation may usefully be approached as the product of interactions 'among Person, Other, and Group or Community'. Although Speier, Mills and Goode used different terms for their three groups, the notion of triadic interactions implies that certain actors are primarily involved in status-creating processes as intermediaries. In their role as intermediaries, they mainly arbitrate by assessing and suggesting particular candidates as possible and plausible recipients of deference from audiences.

In several studies, Espeland and Sauder (Espeland and Sauder 2007, 2016; Sauder 2006; Sauder and Espeland 2009) elaborate upon the US News \& World Report (USN) as an intermediary that modified a long-standing status hierarchy among American law schools. The USN's annual rankings upset a traditionally loose and implicit order, instead introducing strict and explicit procedures for evaluating the worth of law schools, eventually rendering an alternative status hierarchy. The consequences of these evaluations were pervasive for many downgraded schools because they subsequently suffered status losses among some of their main constituencies, such as donors, wealthy parents and prospective students. As a response, several schools altered their profiles, narrowed their intake procedures and manipulated their performance 
indicators, hoping that this would enhance their social standing in the USN's new order.

\section{AIM AND GUIDING QUESTIONS}

I take the work of Espeland and Sauder as a departure point for this book. Much as these two authors conceptualized the USN as an influential intermediary that arbitrated status-creating processes between American law schools and their main constituencies, I will approach the ERC as an authoritative intermediary that arbitrates status-creating processes between its applicants for external research funding and other actors throughout European science. By extension, this also hints at how the ERC's role may stretch past that of a quality arbiter. The idea that evaluations of funding applications can be understood as instances whose significance seemingly extends beyond assessments of scientific quality and allocations of research resources renders it plausible to conceptualize the ERC as a status intermediary in European science.

That said, even though Espeland and Sauder's work provides us with fresh perspectives on the role played by intermediaries in status creation, several questions remain unanswered and open for further exploration. Most importantly, their work has little to say in terms of how certain actors reach positions from which they can credibly arbitrate status-creating processes. Espeland and Sauder predominantly focus on how USN rankings increased the status of some American law schools and decreased the status of others. But we do not learn much about the USN's rise to a position that eventually enabled its annual rankings to affect a long-standing status hierarchy among law schools. More generally, while our knowledge of the consequences that established status intermediaries can engender for candidates is quite advanced, we have a less developed understanding of the ways in which such intermediaries come about. I believe a fruitful path forward is to take the notion of triadic interactions seriously and to focus on the role played by all three groups of actors involved in these very same interactions. As such, I also think it is pertinent to look beyond any unidirectional pictures in which intermediaries only affect candidates. There is more to understand here, particularly in terms of how triadic interactions could have substantial implications for intermediaries and audiences as well. Taking heed of this, I pay particular attention to the interactions between several different actors throughout European science as the ERC successively reached 
a position from which it could arbitrate status-creating processes with credibility.

To advance this extended view of triadic interactions, we need a concept that captures the notion of situations and contexts characterized by struggles and tensions between actors who seek authority in their spheres of social life. One such concept is Pierre Bourdieu's (e.g. Bourdieu 1980, 1985; see also Bourdieu and Wacquant 1992) take on fields. At the very centre of Bourdieusian fields is a relational perspective on the struggles and tensions that engage and affect actors who strive for the authority to influence how the core tenets in their social life spheres are defined and determined. Fields are thus particularly useful for pushing our understanding of how candidates, audiences and intermediaries jointly seem to be engaged in and affected by multiple interactions within which certain attributes and/or behaviours are defined as worthy of status. The focus in Bourdieu's fields on tensions and struggles over authority also makes them well suited for augmenting our knowledge of how some actors are constructed as intermediaries that eventually gain the credibility to determine who and what is status-worthy within their particular spheres of social life.

In sum, throughout this book, my aim is to enhance our knowledge of how certain organizations are constructed as status intermediaries in fields. I explore the antecedents and consequences of the ERC's development in European science to produce new theory that will help us further understand the considerable influence that some intermediaries wield over status-creating processes. My inquiry is guided by three research questions: How are certain organizations constructed as status intermediaries? What aspects drive the development of such intermediaries? And what does this construction imply for the fields in which status intermediaries are active? As has hopefully become apparent by now, these are important questions to pursue, especially when we consider the far-ranging authority that some intermediaries seemingly exert in European science and elsewhere.

\section{BOOK STRUCTURE}

My book is divided into three parts, which are structured as follows. After this introduction, Part I continues with Chapter 2. There, I craft a theoretical framework that builds on a combination of insights from previous literature on status, fields and intermediaries. I deploy this framework to direct my subsequent study of the ERC's development. 
Part II is an empirical section that relies on multiple sources of data, traverses many levels of aggregation, and stretches across several periods of time. In Chapter 3, I use documents as primary means to analyse the historical tensions and struggles that have surrounded the idea of creating a European research funder. Although my analysis reaches back to the 1950 s, my main focus is placed on the early years of the new millennium. I highlight tensions and struggles that jointly provide an important empirical background to the field in which the ERC developed. Moving on, in Chapter 4, I employ a mix of documents, interviews and observations to investigate how the evaluations of applications for funding from the flagship Starting Grant (StG) scheme were organized throughout the ERC's initial budgetary term (that is, 2007-13). I zoom in on the different steps of these evaluations, paying attention to how they were portrayed by the ERC, but also to how they were approached and experienced by a sample of evaluators, applicants, administrators and department heads hailing from the Swedish research context. Then, in Chapter 5, I deploy interviews and observations to explore the perceived consequences of $\mathrm{StG}$ funding allocations. Focusing on Sweden, I analyse how these allocations were believed to affect a sample of scientists, departments and universities that - in one way or another - came into contact with StGs throughout the ERC's inaugural budgetary term. As a point of comparison, I also examine the perceived consequences of a near-identical Swedish funding scheme for ERC StG runners-up.

Part III connects and develops many of the arguments contained throughout this book. In Chapter 6, I tie together my theoretical framework and my empirical section. More specifically, I relate findings to previous literature, ultimately offering a field perspective on the triadic interactions through which the ERC was constructed as a status intermediary in the contexts of Swedish research and European science. I round off with Chapter 7. In it, I suggest contributions, discuss broad implications, acknowledge inherent limitations, and sketch avenues for future research at the nexus of evaluations, intermediaries and status-creating processes in fields.

Readers interested in knowing about the specific methods I based my empirical section upon are invited to read the Appendix. There, I present the different choices, challenges and considerations that characterized my research design, as well as my collection and analysis of document, interview and observation data. I also contemplate how these choices, challenges and considerations successively helped me to close in on the aim of and the research questions that guide this book. 